\title{
The preparation and Research on the Electromagnetic Shielding Effectiveness of T-ZnO@Ag/Silicone Rubber Composites
}

\author{
Jingkai NIE ${ }^{1,2}$ *, Guangke WANG ${ }^{2}$, Dong $\mathrm{HOU}^{2}$, Fu GUO ${ }^{1}, \mathrm{Yu}_{\mathrm{HAN}}{ }^{2}$ \\ ${ }^{1}$ State Key Laboratory of Advanced Power Transmission Technology, Global Energy Inter-connection Research Institute \\ Co. Ltd, Future City for Science and Technology, Changping District, Beijing 102201, P R China \\ ${ }^{2}$ School of Material Science and Engineering, Beijing University of Technology, 100Ping Le Yuan, Chaoyang District, \\ Beijing 100022, P R China
}

crossref http://dx.doi.org/10.5755/j01.ms.26.2.21286

Received 30 July 2018; accepted 14 November 2018

\begin{abstract}
This study first conducted surface modification of Ag-plated Tetrapod-like zinc oxide $(\mathrm{T}-\mathrm{ZnO})$ whiskers with the use of dopamine and prepared Ag-plated T-ZnO whiskers (T-ZnO@ Ag) by means of chemical plating, in which $\mathrm{AgNO}_{3}$ solutions with different concentrations were used during the preparation. Micro-structures of the prepared T-ZnO@Ag powders were examined to evaluate the effect of $\mathrm{AgNO}_{3}$ concentration on $\mathrm{Ag}$ plating performance. Subsequently, conductive Si rubber samples were prepared, the T-ZnO@Ag powders were used as fillers, and the effectiveness of the related electromagnetic shielding was investigated in detail. The results showed that using $\mathrm{AgNO}_{3}$ solution with a concentration of $20 \mathrm{~g} / \mathrm{L}$, a continuous Ag coating-layer was observed on the surface of $\mathrm{T}-\mathrm{ZnO}$ whiskers. It was evident that, when used as fillers, T-ZnO@ Ag has a conductive threshold and when the mass fraction of the fillers exceeded $50 \%$, the T-ZnO@Ag whiskers that were uniformly dispersed in the matrix formed interconnected conductive paths. In this condition, the electromagnetic shielding effectiveness of the prepared T-ZnO@ Ag/Si rubber composite reached up $90 \mathrm{~dB}$. Keywords: electroless plating, Ag-plated T-ZnO whiskers, conductive $\mathrm{Si}$ rubber, electromagnetic shielding; composite material.
\end{abstract}

\section{INTRODUCTION}

Electromagnetic shielding silicon $(\mathrm{Si})$ rubber is currently one of the most favored electromagnetic sealing materials. After processing, it is a kind of functional rubber material and has extensive application in many industries, including aviation and space, ships, computers and power electronics, in which the Si rubber and the conductive fillers are used as the matrix and the shielding agent, respectively [1]. High-conductivity or high-magnetic-conductivity metal powders such as silver $(\mathrm{Ag})$ powder, copper $(\mathrm{Cu})$ powder and nickel $(\mathrm{Ni})$ powder or metallic composite powders such as Ag-coated Ni powders, $\mathrm{Ag}$-coated $\mathrm{Cu}$ powders and $\mathrm{Ag}$ coated aluminum (Al) powders have been used as conductive fillers in conventional electromagnetic shielding $\mathrm{Si}$ rubber $[2,3]$. However, these powder materials have several disadvantages, such as excessive cost, high density, and great filler consumption. There is an urgent need to overcome these issues in the development of electromagnetic shielding technology. Ag-plated or Niplated composite particles that are prepared via chemical deposition, using light-weight and low-cost glass beads, zinc oxide $(\mathrm{ZnO})$, silicon dioxide $\left(\mathrm{SiO}_{2}\right)$ and glass fiber, appear to be attractive conductive fillers that can overcome limitations of conventional fillers [4-10].

Tetrapod-shaped zinc oxide $(\mathrm{T}-\mathrm{ZnO})$ is a kind of crystal whisker with regular three-dimensional structures [11-13]. Because of the advantages, such as light weight, high temperature resistance, and stable chemical properties,
$\mathrm{T}-\mathrm{ZnO}$ now is widely applied as a kind of rubber filler. Despite its poor electromagnetic absorption, the conductivity of $\mathrm{T}-\mathrm{ZnO}$ can be improved by means of electroless plating; because of its special 3D space structure, conductive channels are easily formed in Si rubber, thereby giving it excellent electromagnetic shielding effectiveness (SE) [14].

In recent years, silver plating after modification by dopamine gradually has become a mature preparation route $[15,16]$. Dopamine is a nonhazardous and environmentallyfriendly material. This study first used dopamine for surface modification of $\mathrm{T}-\mathrm{ZnO}$ whiskers, then reduced $\mathrm{Ag}^{+}$by glucose, and finally successfully plated a layer of $\mathrm{Ag}$ on the surface of T-ZnO. After being modified, the dopamine layer on the surface of the $\mathrm{T}-\mathrm{ZnO}$ can be combined with $\mathrm{Ag}^{+}$to form a kind of chelate. Additionally, this study investigated the effect of the concentration of silver nitrate $\left(\mathrm{AgNO}_{3}\right)$ solution on the morphology and conductive performance of the Ag-plated $\mathrm{T}-\mathrm{ZnO}$ and also examined the effect of the mass fraction of $\mathrm{T}-\mathrm{ZnO} / \mathrm{Ag}$ on the conductive and electromagnetic shielding performance of the prepared composite materials.

\section{EXPERIMENTAL PROCEDURE}

\subsection{Material and preparation}

Pure T-ZnO whiskers (99 wt.\%) provided by Chengdu Crystrealm Co., Ltd was used as a raw material. The T-ZnO

\footnotetext{
*Corresponding author. Tel.: +86-15101052027; fax: +86-10-66601541.

E-mail address: niejingkai2018@163.com (J. Nie)
} 
whiskers were placed in deionized water, subjected to suction filtration and elution, and dried for standby application. Firstly, the surface of the $\mathrm{T}-\mathrm{ZnO}$ whiskers was modified. $2 \mathrm{~g} / \mathrm{L}$ dopamine hydrochloride and $0.5 \mathrm{~g} / \mathrm{L}$ trihydroxymethyl aminomethane sulfate (THAMS) was added to a $10 \mathrm{~g} / \mathrm{L} \mathrm{T}-\mathrm{ZnO}$ suspension and the mixture was stirred for 24 hours. After suction filtration and drying, the modified $\mathrm{T}-\mathrm{ZnO}$ whiskers with surface-deposited dopamine were prepared. Next, $\mathrm{AgNO}_{3}$ solutions with different concentrations were prepared and $\mathrm{NH}_{3} \cdot \mathrm{H}_{2} \mathrm{O}$ was added gradually to the prepared $\mathrm{AgNO}_{3}$ solutions for the preparation of silver ammonia solution (also referred to as Tollens' reagent). $0.5 \mathrm{~g} / \mathrm{L}$ povidone (PVP) was then added to the silver ammonia solution for stabilization and dispersion. Subsequently, $10 \mathrm{~g} / \mathrm{L}$ of the dopamine-modified $\mathrm{T}-\mathrm{ZnO}$ whiskers was added to the mixture, which was stirred for 30 minutes so that the suspension of the dopamine-modified T-ZnO whiskers was prepared. During the stirring process, a lot of $\mathrm{Ag}^{+}$ions are adsorbed around the modified $\mathrm{T}-\mathrm{ZnO}$ whiskers due to chelation between the $\mathrm{Ag}^{+}$and the polydopamine. Finally, glucose was added to the mixture as a reducing agent and the $\mathrm{Ag}$-plated layer was deposited on the surface of the $\mathrm{T}-\mathrm{ZnO}$ whiskers. After room-temperature stirring for 1.5 hours, suction filtration and drying, the Ag-plated $\mathrm{T}-\mathrm{ZnO}$ whiskers ( $\mathrm{T}-\mathrm{ZnO} @ \mathrm{Ag}$ ) were prepared.

The inhibitor, Si rubber (3450B), cross-linking agent and $\mathrm{T}-\mathrm{ZnO}$ whiskers before and after Ag plating were added to $\mathrm{Si}$ rubber $(3450 \mathrm{~A})$ in an appropriate order and the mixture was stirred thoroughly. After uniform mixing, the mixtures underwent vacuum defoaming in a vacuum oven and then were poured into cylindrical molds with a diameter of $150 \mathrm{~mm}$ and a thickness of $2 \mathrm{~mm}$. The prepared samples were pressurized and vulcanized on a pressure vulcanizer, during which the vulcanizing temperature and pressure were set as $160{ }^{\circ} \mathrm{C}$ and $15 \mathrm{MPa}$, respectively. Finally, two different kinds of composite material, $\mathrm{T}-\mathrm{ZnO} / \mathrm{Si}$ rubber and $\mathrm{T}-\mathrm{ZnO} @ \mathrm{Ag} / \mathrm{Si}$ rubber, were prepared.

\subsection{XRD and morphology observation}

Phase analysis was conducted using an automatic Xray diffractometer (XRD) (D/Max2200PC, Rigaku, Japan). Scanning electron microscopy (SEM) (ZEISS EVO18, ZEISS Ltd., Germany) was used to observe the distribution of the fillers in the composites and their tensile fracture morphology.

\subsection{Measurements of SE}

The SE of samples under plane-wave conditions was measured by means of the flange coaxial method. The setup consisted of a DN15115 SE tester, which was connected to an Agilent 4396B RF network spectrum impedance analyzer. The scanning frequency ranged from $100 \mathrm{MHz}$ to $1.5 \mathrm{GHz}$. The thickness of the rubber layers was $2 \mathrm{~mm}$.

\section{RESULTS AND DISCUSSION}

The XRD patterns of T-ZnO whiskers before and after Ag plating are shown in Fig. 1. It can be observed that XRD spectrum of $\mathrm{T}-\mathrm{ZnO}$ fits perfectly with the standard XRD spectrum of $\mathrm{ZnO}$ with hexagonal Wurtzite structure.
Additionally, the XRD spectrum of T-ZnO exhibits narrow and sharp diffraction peaks and no other unknown peaks, suggesting that the prepared $\mathrm{T}-\mathrm{ZnO}$ was characterized by high crystallinity and excellent purity. After chemical silvering, the diffraction peaks of face-centered cubic $\mathrm{Ag}$ (1 111$), \quad(200),(2 \quad 20)$ and (3 111$)$ were located at $2 \theta=38.2^{\circ}, 44.4^{\circ}, 64.6^{\circ}$ and $76.7^{\circ}$, respectively. The observations confirmed that the $\mathrm{T}-\mathrm{ZnO}$ whiskers were coated by Ag on the outside surface, which can affect both the adsorption and scattering of the $\mathrm{T}-\mathrm{ZnO}$ spectrum. Moreover, the $\mathrm{T}-\mathrm{ZnO} @ \mathrm{Ag}$ particles were larger, thereby weakening the diffraction peaks of the $\mathrm{T}-\mathrm{ZnO}$.

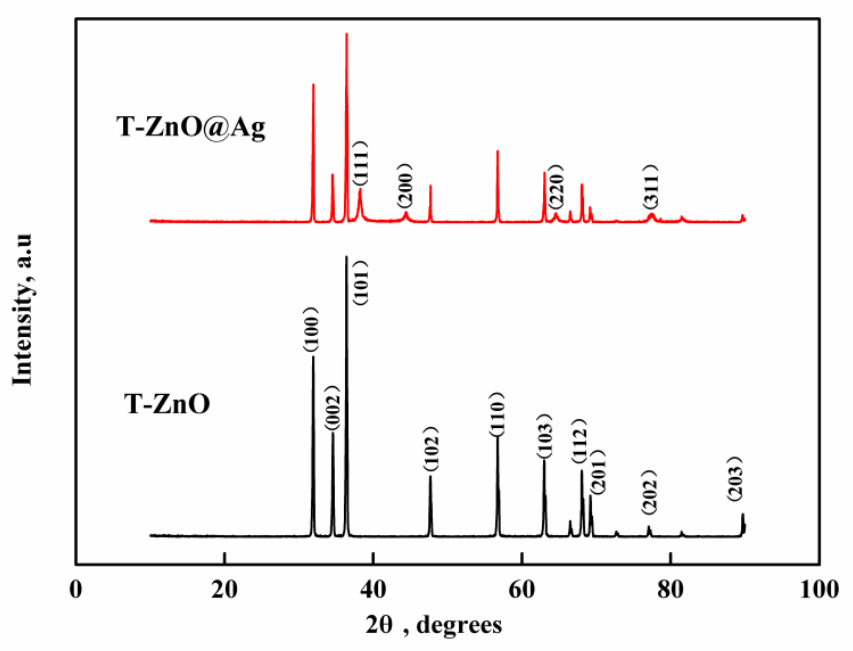

Fig. 1. XRD patterns of the prepared $\mathrm{T}-\mathrm{ZnO}$ and $\mathrm{T}-\mathrm{ZnO} @ \mathrm{Ag}$ whiskers

The morphologies of the prepared T-ZnO, T-ZnO@Ag whiskers and Si-rubber-based composite materials are shown in the SEM micrographs presented in Fig. 2. As shown in Fig. 2 a, the T-ZnO whiskers had a smooth surface appearance, the lengths of the tetrapod-like whiskers ranged from 10 to $30 \mu \mathrm{m}$, the base diameter was approximately $0.8 \sim 1.5 \mu \mathrm{m}$, and the angle between any two whiskers was nearly $109^{\circ}$. Fig. 2 b shows the SEM image of T-ZnO@ Ag that was prepared using $10 \mathrm{~g} / \mathrm{L} \mathrm{AgNO}_{3}$ solution, from which it can be observed that the formation of the Ag layer on the surface of $\mathrm{T}-\mathrm{ZnO}$ whiskers was discontinuous and incomplete and there was an increase in the diameter of the T-ZnO whiskers. Fig. $2 \mathrm{c}$ shows the SEM image of T$\mathrm{ZnO} @ \mathrm{Ag}$ that was prepared using the $20 \mathrm{~g} / \mathrm{L} \mathrm{AgNO}_{3}$ solution. The $\mathrm{T}-\mathrm{ZnO}$ whiskers were coated with a complete and compact Ag layer obviously. Fig. $2 \mathrm{~d}$ shows an SEM image of T-ZnO@Ag that was prepared using the $30 \mathrm{~g} / \mathrm{L}$ $\mathrm{AgNO}_{3}$ solution, from which it can be observed that the $\mathrm{Ag}$ layer on the surface of $\mathrm{T}-\mathrm{ZnO}$ whiskers was thicker and more compact than was the case in Fig. 2 b and Fig. 2 c. Fig. $2 \mathrm{e}-\mathrm{h}$ ) display SEM images of the composite materials of Si rubber and T-ZnO@Ag whiskers that were prepared using different concentrations. It can be observed that the T$\mathrm{ZnO} @ \mathrm{Ag}$ whiskers were uniformly staked in the Si rubber matrix and formed an interconnected conductive network.

Volume resistivity also is an important parameter for shielding materials. The T-ZnO@Ag power was made into a cylindrical piece with a size of about $\Phi 10 \times 1 \mathrm{~mm}$, and the resistivity was tested by four-probe method. Three samples 
were tested for each concentration, and three points were measured for each sample.
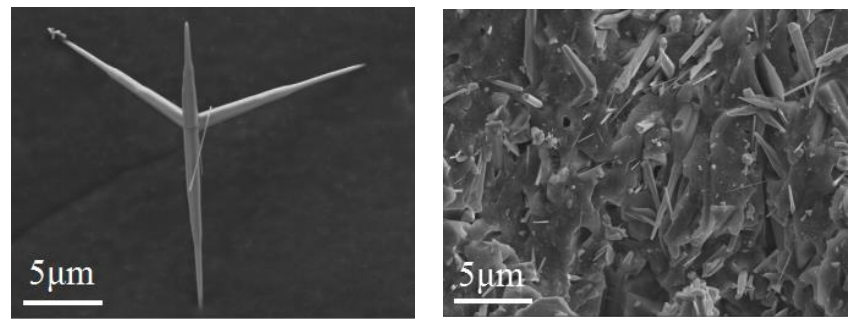

a

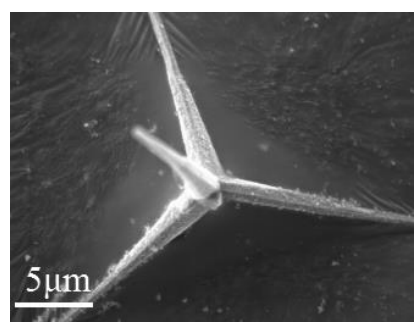

b

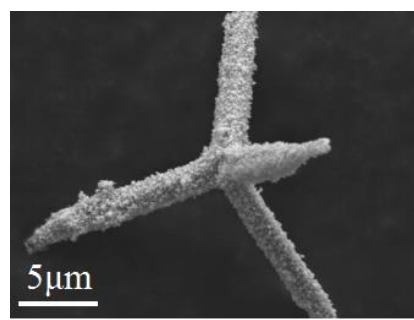

c

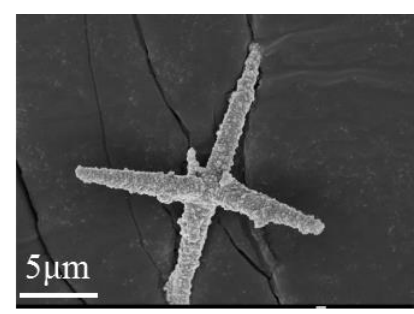

d

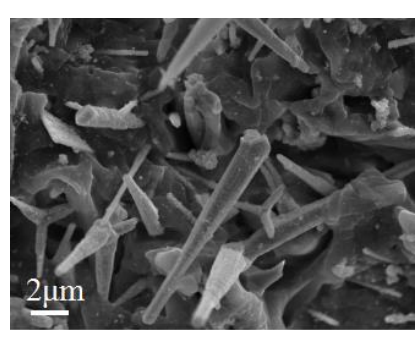

f

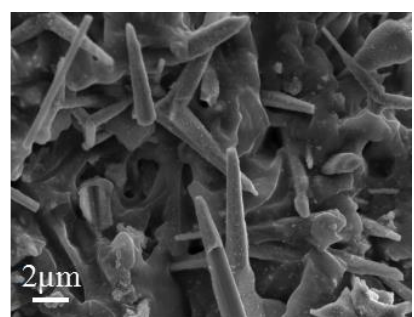

$\mathrm{g}$

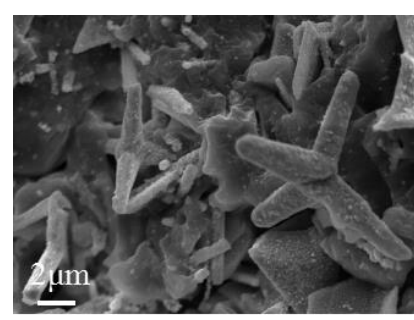

$\mathrm{h}$

Fig. 2. SEM images of T-ZnO (a) and T-ZnO@Ag whiskers that were prepared using different concentrations of $\mathrm{AgNO}_{3}$ : $\mathrm{b}-10 \mathrm{~g} / \mathrm{L} ; \mathrm{c}-20 \mathrm{~g} / \mathrm{L} ; \mathrm{d}-30 \mathrm{~g} / \mathrm{L}$; SEM images of different Si-rubber-based composite materials: e-T-ZnO/Si rubber; $\mathrm{f}, \mathrm{h}-\mathrm{T}-\mathrm{ZnO} @ \mathrm{Ag} / \mathrm{Si}$ rubber $(10 \mathrm{~g} / \mathrm{L}, \quad 20 \mathrm{~g} / \mathrm{L}, \quad 30 \mathrm{~g} / \mathrm{L}$ $\left.\mathrm{AgNO}_{3}\right)$.

Table 1. Volume resistivities of $\mathrm{T}-\mathrm{ZnO} @ \mathrm{Ag}$ powder and $\mathrm{T}$ $\mathrm{ZnO} @ \mathrm{Ag} / \mathrm{Si}$ rubber composite materials when different concentrations of $\mathrm{AgNO}_{3}$ solutions were used

\begin{tabular}{|c|c|c|c|}
\hline $\begin{array}{c}\text { Sample } \\
\text { No. }\end{array}$ & $\begin{array}{c}\text { Concentration of } \\
\mathrm{AgNO}_{3} \text { solution, } \\
\mathrm{g} / \mathrm{L}\end{array}$ & $\begin{array}{c}\text { Volume resistivity } \\
\text { of T-ZnO@Ag, } \\
\Omega \cdot \mathrm{cm}\end{array}$ & $\begin{array}{c}\text { Volume resistivity } \\
\text { of T-ZnO@ } \mathrm{Ag} / \mathrm{Si} \\
\text { rubber, } \Omega \cdot \mathrm{cm}\end{array}$ \\
\hline 1 & 10 & $1.69 \times 10^{-2}$ & $3.43 \times 10^{-1}$ \\
\hline 2 & 20 & $2.51 \times 10^{-4}$ & $1.04 \times 10^{-3}$ \\
\hline 3 & 30 & $2.34 \times 10^{-4}$ & $1.03 \times 10^{-3}$ \\
\hline
\end{tabular}

The composite resistivity test method is similar to powder, and the sample size is $\Phi 150 \times 2 \mathrm{~mm}$. All resistivity test data are on the same order of magnitude.The final data

list in the tabal 1 is the intermediate value. Table 1 lists the volume resistivities of the $\mathrm{T}-\mathrm{ZnO} @ \mathrm{Ag}$ powder and the $\mathrm{T}$ $\mathrm{ZnO} @ \mathrm{Ag} / \mathrm{Si}$ rubber composite materials when different concentrations of $\mathrm{AgNO}_{3}$ were used. The volume resistivity of the T-ZnO@Ag powder that was prepared using $10 \mathrm{~g} / \mathrm{L}$ $\mathrm{AgNO}_{3}$ was $1.69 \times 10^{-2} \Omega \cdot \mathrm{cm}$. As the concentration of $\mathrm{AgNO}_{3}$ was increased to $20 \mathrm{~g} / \mathrm{L}$, the volume resistivity of the T-ZnO@Ag powder decreased to $2.51 \times 10^{-4} \Omega \cdot \mathrm{cm}$. With further increase in the concentration of the $\mathrm{AgNO}_{3}$ solution, the volume resistivity of the $\mathrm{T}-\mathrm{ZnO} @ \mathrm{Ag}$ powder remained almost unchanged. This was due to the fact that, using $20 \mathrm{~g} / \mathrm{L} \mathrm{AgNO}_{3}$ solution, a continuous and compact $\mathrm{Ag}$ layer was formed on the surface of the $\mathrm{T}-\mathrm{ZnO}$. The measurement results for volume resistivity are in good agreement with the SEM observations. The optimal concentration of $\mathrm{AgNO}_{3}$ in the preparation of the whiskers was determined to be $20 \mathrm{~g} / \mathrm{L}$.

According to percolation theory, fillers that originally were isolated and scattered can form continuous conductive paths when the volume fraction of the filler reaches a critical value. At the macro level, the volume resistivity of the composite system decreased suddenly, accompanied by an abrupt increase in the electromagnetic shielding performance. Fig. 3 shows the variation in the conductivity of the composites with different mass fractions of fillers. When the mass fraction of the filler was $50 \%$, the conductivity of the composite reached $1000 \mathrm{~S} / \mathrm{cm}$. The conductivity of the composite increased abruptly at a mass fraction of $40 \%-50 \%$ of filler, suggesting that the percolation threshold of the T-ZnO@Ag particles was $40 \%-50 \%$ and the corresponding mass fraction of the filler was 80-100 phr. Compared with glass beads and carbonyl-modified $\mathrm{Ni}$ powders, significantly fewer $\mathrm{T}$ $\mathrm{ZnO} @ \mathrm{Ag}$ particles were used in this kind of composite material $[17,18]$.

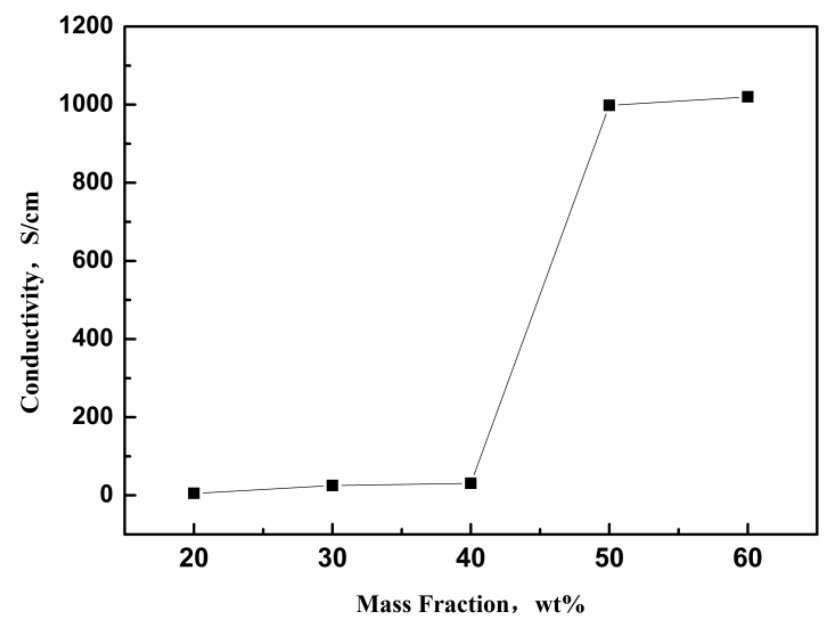

Fig. 3. Relationship between the mass fraction of filler and the conductivity of the composite

In combination with the above analysis of the percolation threshold, the mass fraction of $\mathrm{T}-\mathrm{ZnO} @ \mathrm{Ag}$ particles in this study was determined to be $50 \%$. Next, the electromagnetic shielding effectiveness of the three different kinds of $\mathrm{T}-\mathrm{ZnO} @ \mathrm{Ag} / \mathrm{Si}$ rubber composites that were prepared using different concentrations of $\mathrm{AgNO}_{3}$ solution were examined, and the test results are displayed in Fig. 4. When the concentration of $\mathrm{AgNO}_{3}$ was $10 \mathrm{~g} / \mathrm{L}$, the 
electromagnetic shielding effectiveness is only about $30 \mathrm{~dB}$ because the Ag particles on the $\mathrm{T}-\mathrm{ZnO}$ whiskers surface were not covered completely, as the concentration of $\mathrm{AgNO}_{3}$ was increased to $20 \mathrm{~g} / \mathrm{L}$, the electromagnetic shielding effectiveness suddenly increased to $90 \mathrm{~dB}$. It was due to a three-dimensional mesh structure with a certain size formed in the $\mathrm{T}-\mathrm{ZnO} /$ silicone rubber composite materials. The innumerable ring-shaped conductive flow networks made of $\mathrm{T}-\mathrm{ZnO}$ whiskers could disspate electromagnetic wave energy when the electromagnetic wave entered into the composite material, in addition, $\mathrm{T}-\mathrm{ZnO}$ has a large aspect ratio, the sharp needle tip was likely to form a local strong electric field under the influence of the external electric field. In this case, all the needle tip of $\mathrm{T}-\mathrm{ZnO}$ whiskers as an electric dipole resonated with the coming electromagnetic to reduce electromagnetic wave energy [12].

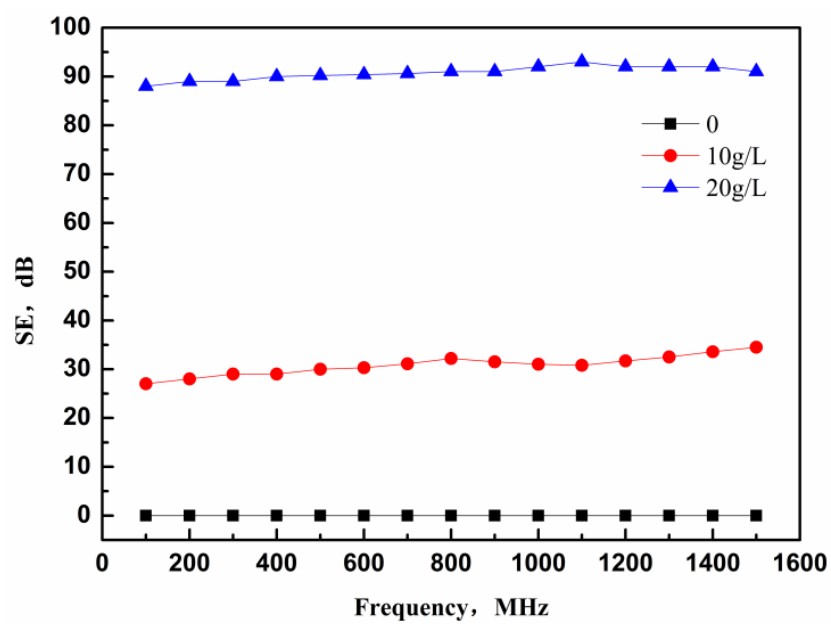

Fig. 4. The effectiveness of electromagnetic shielding by the conductive si rubber filled with the silver-coated $\mathrm{T}-\mathrm{ZnO}$ powders with different silver nitrate contents: $0,10 \mathrm{~g} / \mathrm{L}$ and $20 \mathrm{~g} / \mathrm{L}$

According to the electromagnetic shielding theory proposed by Schelkunoff, the shielding effectiveness (SE) of a material can be written as:

$S E=R+A+B$,

where $R, A$ and denotes the losses caused by reflection, absorption and multiple reflections, with a unit of $\mathrm{dB}$.

In case of $A>10 \mathrm{~dB}, \mathrm{~B}$ is negligible and Eq. 1 can be simplified as:

$S E=R+A$,

Specifically,

$R=168-10 \lg (f \mu / \sigma)$.

and

$A=1.31 t \sqrt{f \mu \sigma}$,

where $\mu$ and $\sigma$ denote the relative permeability and conductivity of the shielding material, respectively; $f$ denotes the electromagnetic frequency, with a unit of $\mathrm{Hz} ; t$ denotes the thickness of the shielding material, with a unit of $\mathrm{mm}$.
It can be concluded that the decline in volume resistivity can increase both reflection loss (R) and adsorption loss (A), thereby enhancing shielding effectiveness. In conclusion, with increasing concentration of the $\mathrm{AgNO}_{3}$ solution, the electromagnetic shielding effectiveness of the $\mathrm{T}$ $\mathrm{ZnO} @ \mathrm{Ag} / \mathrm{Si}$ rubber composite was increased.

\section{CONCLUSIONS}

This study first prepared Ag-plated T-ZnO whiskers through dopamine modification and chemical Ag plating, in which different concentrations of $\mathrm{AgNO}_{3}$ solutions were used, and then prepared different conductive $\mathrm{Si}$ rubber samples in which both $\mathrm{T}-\mathrm{ZnO}$ and $\mathrm{T}-\mathrm{ZnO} @ \mathrm{Ag}$ were used as the conductive fillers, respectively. Moreover, the micromorphologies of the $\mathrm{T}-\mathrm{ZnO} @ \mathrm{Ag}$ whiskers and the electromagnetic shielding effectiveness of the prepared conductive $\mathrm{Si}$ rubber composites were examined in depth.

$\mathrm{T}-\mathrm{ZnO}$ exhibited a representative hexagonal Wurtzite structure with a regular and smooth surface. Using $\mathrm{AgNO}_{3}$ solution with a concentration of $20 \mathrm{~g} / \mathrm{L}$, the surface of T$\mathrm{ZnO}$ whiskers can be coated with a continuous and complete Ag layer.

After being added to Si rubber, the T-ZnO@Ag powder can be dispersed uniformly in the matrix, whose conductive threshold was $50 \mathrm{wt} \%$. In terms of filler consumption and conductivity, the prepared conductive Si rubber, in which T$\mathrm{ZnO} @ \mathrm{Ag}$ powder was used as the filler exceeded the electromagnetic shielding performance of composites with other fillers. The new composites offer the prospect of wide application.

When the mass fraction of $\mathrm{T}-\mathrm{ZnO} @ \mathrm{Ag}$ was $50 \%$, the conductivity of the Si-rubber-based composite reached $1000 \mathrm{~S} / \mathrm{cm}$, and the shielding effectiveness at an electromagnetic frequency range of $100-1500 \mathrm{MHz}$ was up to $90 \mathrm{~dB}$, suggesting that the $\mathrm{T}-\mathrm{ZnO} @ \mathrm{Ag}$ powder formed interconnected conductive paths in the matrix. Thus, T$\mathrm{ZnO} @ \mathrm{Ag} / \mathrm{Si}$ rubber composites have a bright future in electromagnetic shielding service.

\section{Acknowledgment}

The authors greatly appreciate the financial support by State Corporation of China and Global Energy Interconnection Research Institute Co.Ltd.

\section{REFERENCES}

1. Zhang, J., Zhang, S.Y., Feng, S.Y., Jiang, Z.G. The Correlativity of Positive Temperature Coefficient Effects in Conductive Silicone Rubber Polymer International 54 (8) 2005: pp. $1175-1179$.

https://doi.org/10.1002/pi.1826

2. Vishwanath, S.K., Kim, D.G., Kim, J. Electromagnetic Interference Shielding Effectiveness of Invisible Metal-mesh Prepared by Electrohydrodynamic Jet Printing Japanese Journal of Applied Physics 53 (5S3) 2014: pp. 05HB11. https://doi.org/10.7567/JJAP.53.05HB11

3. Moon, Y.E., Yun, J., Kim, H.I. Synergetic Improvement in Electromagnetic Interference Shielding Characteristics of Polyan-iline Coated Graphite Oxide $/ \gamma-\mathrm{Fe}_{2} \mathrm{O}_{3} / \mathrm{Ba} \quad \mathrm{TiO}_{3}$ Nanocomposites Journal of Industrual \& Enigineering Chemistry 19 (2) 2013: pp.493-497. http://dx.doi.org/10.1016/j.jiec.2012.09.002 
4. Petukhov, D.I., Kirikova, M.N., Bessonov, A.A., Bailey, M.J.A. Nickel and Copper Conductive Patterns Fabricated by Reactive Inkjet Printing Combined with Electroless Plating Materials Letters 132 (132) 2014: pp. $302-306$. http://dx.doi.org/10.1016/j.matlet.2014.06.109

5. AL-Oqla, F.M., Sapuan, S.M., Anwer, T., Jawaid, M., Hoque, M.E. Natural Fiber Reinforced Conductive Polymer Composites as Functional Materials: A Review Synthetic Metals 206 2015: pp. 42-54. http://dx.doi.org/10.1016/j.synthmet.2015.04.014

6. Wang, W.C., Jiang, Y., Liao, Y., Tian, M., Zou, H., Zhang, L.Q. Fabrication of Silver-coated Silica Microspheres through Mussel-inspired Surface Functionalization Journal of Colloid \& Interface Science 358 (2) 2011: pp. $567-574$. https://doi.org/10.1016/j.jcis.2011.03.023

7. Zakaria, M.Y., Sulong, A.B., Sahari, J., Suherman, H. Effect of the Addition of Milled Carbon Fiber as A Secondary FIller on the Electrical Conductivity of Graphite/ Epoxy Composites for Electrical Conductive Material Composites Part $B \quad 83$ 2015: pp. 75-80.

8. Li, L.B., Liu, B. Study of Ni-catalyst for Electroless Ni-P Deposition on Glass Fiber Materials Chemistry \& Physics 128 (1) 2011: pp. 303-310.

https://doi.org/10.1016/j.matchemphys.2011.03.026

9. Hu, Y.J., Zhang, H.Y., Li, F., Chen, T.L. Investigation into Electrical Conductivity and Electromagnetic Interference Shielding Effectiveness of Silicone Rubber Filled with Agcoated Cenosphere Particles Polymer Testing 29 (5) 2010: pp. 609-612. https://doi.org/10.1016/j.polymertesting.2010.03.009

10. Wnag, R., Yang, H., Wang, J.L., Li, F.X. The Electromagnetic Interference Shielding of Silicone Rubber Filled with Nickelcoated Carbon Fiber Polymer Testing 38 (18) 2014: pp. 53-56.

http://dx.doi.org/10.1016/j.polymertesting.2014.06.008

11. Nam, Ki-Ho., Kim, D., Seo, J., Han, H. Effect of Tetrapod $\mathrm{ZnO}$ whiskers on the Physical and Moisture Barrier Properties of Transparent Polyimide/TZnO-W Composite Films Macromolecular Research 22 (12) 2014: pp. 1243-1252. https://doi.org/10.1007/s13233-014-2187-6
12. Rackauskas, S., Klimova, O., Jiang, H., Nikitenko, A., Chernenko, K.A., Shandakov, S.D., Kauppinen, E.I., Tolochko, O.V., Nasibulin, A.G. A Novel Method for Continuous Synthesis of $\mathrm{ZnO}$ Tetrapods The Journal of Physical Chemistry C 119 (28) 2015: pp. 16366-16373. https://doi.org/10.1021/acs.jpcc.5b03702

13. Rackauskas, S., Mustonen, K., Järvinen, T., Mattila, M., Klimova, O., Jiang, H., Tolochko, O., Lipsanen, H., Kauppinen, E.I., Nasibulin, A.G. Synthesis of $\mathrm{ZnO}$ Tetrapods for Flexible and Transparent UV Sensors Nanotechnology 23 (9) 2012: pp. 095502. http://dx.doi.org/10.1088/0957-4484/23/9/095502

14. Zhou, Z.W., Chu, L.S., Hu, S.C. Microwave Absorption Behaviors of Tetra-needle-like $\mathrm{ZnO}$ Whiskers Materials Science \& Engineering B 126 (1) 2006: pp. 93-96. https://doi.org/10.1016/j.mseb.2005.09.009

15. Yang, D., Tian, M., Wang, W.C. Li, D.D., Li, R.Y., Zhang, L.Q. Controllable Dielectric and Electrical Performance of Polymer Composites with Novel Core/shellStructured Conductive Particles through Biomimetic Method Electrochimica Acta 87 (1) 2013: pp. 9-17. http://dx.doi.org/10.1016/j.electacta.2012.08.122

16. Xu, C.H., Tian, M., Liu, H., Zhang, L.Q., Wang, W.C. Fabrication and Properties of Silverized Glass Fiber by Dopamine Functionalization and Electroless Plating Journal of the Electrochemical Society 159 (4) 2012: pp. D217-D224. https://doi.org/10.1149/2.056204jes

17. Xiao, W.M., Lei, Y.P., Xia, Z.D., Chen, X., Han, Y., Nie, J.K. Effect of Silver Plating on the Properties of Conductive Silicone Rubber Filled with Silver-coated Carbonyl Nickel Powder Journal of Alloys \& Compounds 724 2017: pp. 24-28. http://dx.doi.org/10.1016/j.jallcom.2017.07.021

18. Gao, X.G., Zhang, H.Y. Investigation into Conductivity of Silver-coated Cenosphere Composities Prepare by Amodified Electroless Process Applied Surface Science 264 (1) 2013: pp. $756-760$. http://dx.doi.org/10.1016/j.apsusc.2012.10.1 